\title{
PRAIRIEMAP: A GIS Database for Prairie Grassland Management in Western North America
}

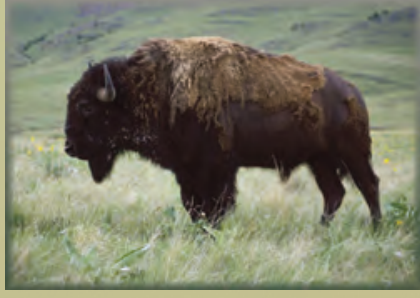

American bison Bison bison

The USGS Forest and Rangeland Ecosystem Science Center, Snake River Field Station (SRFS) maintains a database of

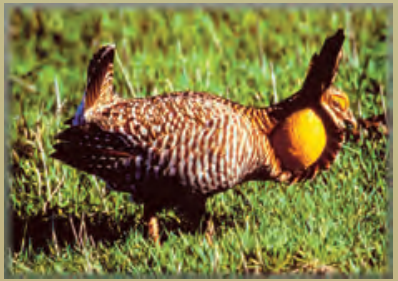

Attwater's prairie chicken

Tympanuchus capido attwateri spatial information, called PRAIRIEMAP, which is needed to address the management of prairie grasslands in western North America. We identify and collect spatial data for the region encompassing the historical extent of prairie grasslands (Figure 1). State and federal agencies, the primary entities responsible for management of prairie grasslands, need this information to develop proactive management strategies to prevent prairie-grassland wildlife species from being listed as Endangered Species, or to develop appropriate responses if listing does occur. Spatial data are an important component in documenting current habitat and other environmental conditions, which can be used to identify areas that have undergone significant changes in land cover and to identify underlying causes. Spatial data will also be a critical component guiding the decision processes for restoration of habitat in the Great Plains. As such, the PRAIRIEMAP database will facilitate analyses of largescale and range-wide factors that may be causing declines in grassland habitat and populations of species that depend on it for their survival. Therefore, development of a reliable spatial database carries multiple benefits for land and wildlife management. The project consists of 3 phases: (1) identify relevant spatial data, (2) assemble, document, and archive spatial data on a computer server, and (3) develop and maintain the web site (http://prairiemap.wr.usgs.gov) for query and transfer of GIS data to managers and researchers.

\section{Introduction}

Grasslands once dominated central North America, but have undergone radical and rapid changes in the past century. The PRAIRIEMAP

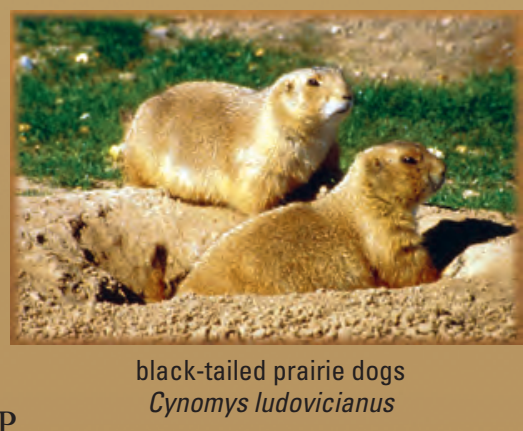
project was developed in response to growing concern among scientists and resource managers over significant declines in grassland ecosystems and the wildlife species that depend on them for their survival, also known as obligate species.

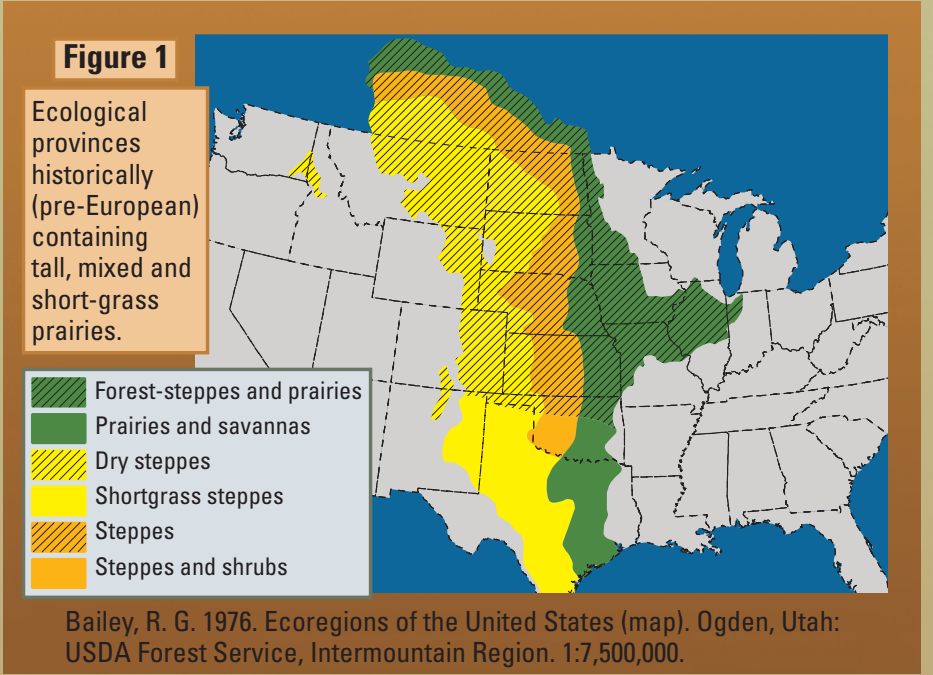

Declines have been greatest in the tall-grass prairie, with losses exceeding those reported for any other major ecological community in North America. Less than $1 \%$ of the preEuropean settlement tall-grass prairie remains. Estimated declines for the mixed-grass prairie are also extreme, and declines in short-grass prairie have generally been much less than in either tall or mixed-grass prairies, but are still considerable.

As a result of this habitat loss, which has been associated with factors including agricultural development, overgrazing of livestock, oil and gas exploration, and

Grassland-obligate species, such as the blackfooted ferret (Mustela nigripes) have been nearly extirpated due to loss of native grasslands.

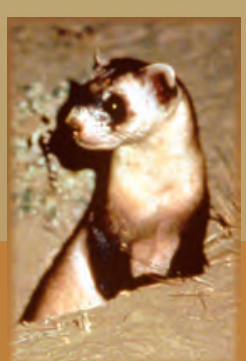

expansion of exotic species, many populations of prairie obligates have declined or are now absent from large portions of their historical range. One such species is the black-tailed prairie dog (Cynomys ludovicianus), which has experienced an estimated $98 \%$ decline in numbers since European settlement. Many species closely associated with the prairie dog are either listed or are being reviewed for listing as Endangered or Threatened, such as the black-footed ferret (Mustella nigripes), swift fox (Vulpes velox), and mountain plover (Charadrius montanus). Another group that has been severely affected are endemic grassland bird species, which have shown more widespread, and steeper declines than any other group of North American bird species. 


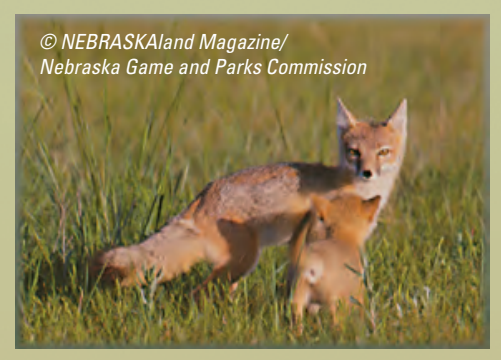

swift fox

Vulpes velox
Spatial data are important to our understanding of factors causing the loss of grassland habitats and the associated declines in many grassland-obligate species of wildlife. Spatial data can also play a critical role in issues such as the review process for listing of black-tailed prairie dogs as an Endangered Species or to help guide decisions on restoration of habitat in the Great Plains. For the short, mixed, and tall-grass regions in western North America, spatial data currently are limited in the extent of coverage, not readily accessible because of computer software or hardware incompatibility, or may not be available in digital format. Therefore, collecting, documenting, and making common datasets available for subsequent analyses are critical components in the management of grassland habitats.

Federal and state land and wildlife agencies currently need spatial data that are readily available and documented to properly address these critical issues in the management

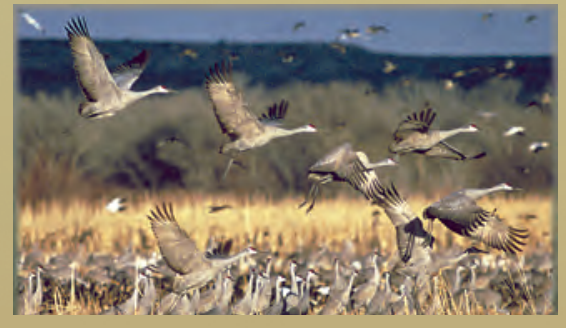

sandhill cranes Grus canadensis of prairie grasslands in western North America. Therefore, the goal of the PRAIRIEMAP project, developed by the USGS Forest and Rangeland Ecosystem Science Center, Snake River Field Station is to collect and maintain spatial data layers and disseminate them on the PRAIRIEMAP website.

\section{Methods}

\section{Identify Relevant Spatial Data}

Identifying all relevant data is an ongoing component in developing and maintaining the spatial database. This work requires extensive searching for information contained in offices of state and federal agencies, universities, and privately-owned data.

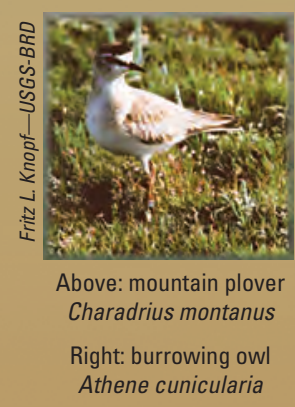

\section{Assemble, Document, and Archive Spatial Data}

We have assembled maps of current vegetation (such as the GAP vegetation map), and maps of habitat change (USGS Land Cover Change Maps), and other datasets important for understanding processes that influence wildlife population declines. We will emphasize maps that cover the entire historic prairie grassland range. Spatial data that is relevant to grassland management, such as prairie dog colonies, and any local coverages identified by researchers and managers is also emphasized. When the data set is not readily accessible or may be proprietary, sources are identified and appropriate links to the site are established. Ancillary maps, such as road networks, are also collected.

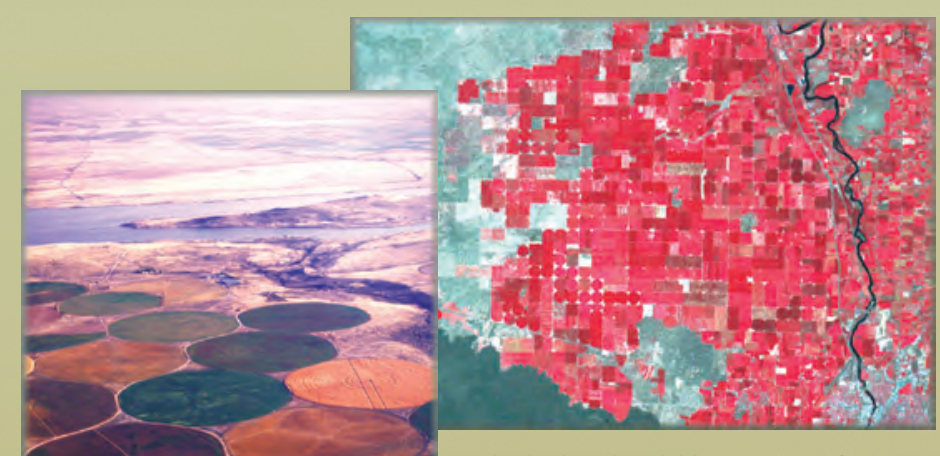

Agricultural activities are one of the major land uses in the North American Great Plains. The habitat changes associated with these activities have been linked to impacts on populations of wildlife that depend on prairie grasslands for their survival.

\section{Develop the Website, File Transfer and Map Display}

The PRAIRIEMAP web site (http://prairiemap.wr.usgs.gov) contains links to partners, documentation of the data, and a directory of GIS data that can be downloaded by researchers and managers. Spatial data are in a variety of formats, including ArcInfo and ArcView. Each layer has a description of the geographical coverage, date of the coverage, and description of the data attributes. Where possible, the assessment of accuracy is included in the documentation for each GIS layer. Users can search for data using form-based queries and will ultimately be able to search using spatial display (ArcIMS) queries.
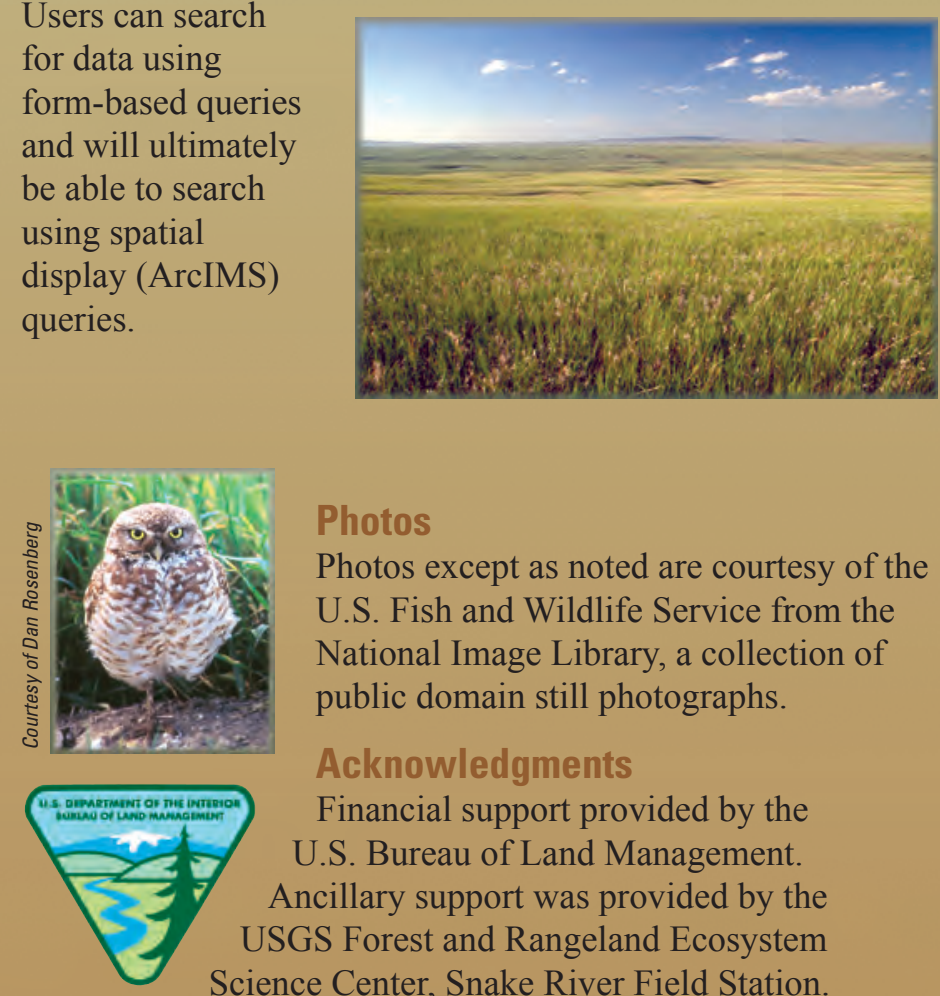

\section{Photos}

Photos except as noted are courtesy of the U.S. Fish and Wildlife Service from the National Image Library, a collection of public domain still photographs.

\section{Acknowledgments}

Financial support provided by the U.S. Bureau of Land Management. Ancillary support was provided by the USGS Forest and Rangeland Ecosystem Science Center, Snake River Field Station.

\section{Contacts}

USGS Forest and Rangeland Ecosystem Science Center, Snake River Field Station, 970 Lusk Street, Boise, ID 83706 Cara W. Meinke, 208-426-2696; cara_meinke@usgs.gov Steven T. Knick, 208-426-5208; steve_knick@usgs.gov Linda S. Schueck, 208-426-3353; 1schueck@usgs.gov 